\title{
Modeled steric and mass-driven sea level change caused by Greenland Ice Sheet melting
}

\author{
S.-E. Brunnabend ${ }^{\mathrm{a}}$, J. Schröter ${ }^{\mathrm{a}}$, R. Timmermann ${ }^{\mathrm{a}}$, R. Rietbroek ${ }^{\mathrm{b}}$, J. \\ Kusche $^{\mathrm{b}}$ \\ ${ }^{a}$ Alfred Wegener Institute for Polar and Marine Research, Bremerhaven, Germany \\ ${ }^{b}$ Institute of Geodesy and Geo-information, Bonn University, Bonn, Germany
}

\begin{abstract}
Meltwater from the Greenland Ice Sheet (GIS) has been a major contributor to sea level change in the recent past. Global and regional sea level variations caused by melting of the GIS are investigated with the finite element sea-ice ocean model (FESOM). We consider changes of local density (steric effects), mass inflow into the ocean, redistribution of mass, and gravitational effects. Five melting scenarios are simulated, where mass losses of 100, 200, 500, and $1000 \mathrm{Gt} / \mathrm{yr}$ are converted to a continuous volume flux that is homogeneously distributed along the coast of Greenland south of $75^{\circ} \mathrm{N}$. In addition, a scenario of regional melt rates is calculated from daily ice melt characteristics. The global mean sea level modeled with FESOM increases by about $0.3 \mathrm{~mm} / \mathrm{yr}$ if $100 \mathrm{Gt} / \mathrm{yr}$ of ice melts, which includes eustatic and steric sea level change. In the global mean the steric contribution is one order of magnitude smaller than the eustatic contribution. Regionally, especially in the North Atlantic, the steric contribution leads to strong deviations from the global mean sea level change. The modeled pattern mainly reflects the structure of temperature
\end{abstract}

Email address: Sandra-Esther.Brunnabend@awi.de (S.-E. Brunnabend) 
and salinity change in the upper ocean. Additionally, small steric variations occur due to local variability in the heat exchange between the atmosphere and the ocean. The mass loss has also affects on the gravitational attraction by the ice sheet, causing spatially varying sea level change mainly near the GIS, but also at greater distances. This effect is accounted for by using Green's functions.

Keywords: Sea level change, Greenland, ice sheet melting, gravitational attraction

\section{Introduction}

2 During the last decades, global mean sea level has risen due to climate 3 change (Church et al., 2001). The increase in mean temperature results in 4 a thermal expansion of the ocean, which causes about $60 \%$ of the observed 5 sea level rise (Bindoff et al., 2007). Another significant contribution to sea 6 level change arises from the ice mass loss in ice covered regions, especially

7 Greenland and Antarctica. Recently, numerous studies have investigated 8 mass variations of ice sheets using observations from the satellite mission 9 GRACE (Gravity Recovery and Climate Experiment, Tapley et al. (2004)). ${ }_{10}$ These studies motivate the melt rates that are used in the simulations of this 11 study. For example, ice mass loss of $101 \pm 16 \mathrm{Gt} / \mathrm{yr}$ in Greenland between 122003 and 2005 was derived from GRACE data by Luthcke et al. (2006). The 13 observations indicated a mass loss of $155 \mathrm{Gt} / \mathrm{yr}$ below $2000 \mathrm{~m}$ and a gain 14 of ice mass at higher elevations, with a strong seasonal cycle below 2000

m. Wouters et al. (2008) estimated an ice mass loss of $179 \pm 26 \mathrm{Gt} / \mathrm{yr}$ in Greenland between 2003 and 2007, including a negative mass balance above 
$2000 \mathrm{~m}$ in 2007. The loss of Greenland and Antarctic ice mass was estimated by Velicogna (2009) for the period between April 2002 and February 2009 again using GRACE measurements. For the GIS, a mass loss of $137 \mathrm{Gt} / \mathrm{yr}$ was found between 2002 and 2003, and 286 Gt/yr between 2007 and 2009, while an ice mass loss of $143 \pm 73 \mathrm{Gt} / \mathrm{yr}$ was estimated for the Antarctic Ice Sheet. Gunter et al. (2009) compared mass variations in Antarctica derived from the GRACE and ICESat missions. Both datasets showed similar mass losses of about $100 \mathrm{Gt} / \mathrm{yr}$, mainly located at the West Antarctic Ice Sheet. These findings agree with a study by Rignot et al. (2008), who estimated a similar mass loss in the Antarctic in year 2000 using interferometric syntheticaperture radar data from various remote sensing satellite missions. During the entire period of investigation (1996 to 2006) they found an increasing rate of ice mass loss, from $78 \mathrm{Gt} / \mathrm{yr}$ in 1996 to $153 \mathrm{Gt} / \mathrm{yr}$ in 2006.

The fresh water inflow from the two major ice sheets causes sea level rise and as a consequence strongly influences the state of the ocean. Density variations change sea level locally due to the freshening of the ocean. Gerdes et al. (2006) investigated this reaction of the ocean to fresh water anomalies caused by the GIS melting under different boundary conditions. From their simulations they inferred reduced overturning and gyre circulation in the North Atlantic. Stammer (2008) investigated, along with salinity and temperature variations, the response of the sea surface height ( $\mathrm{SSH}$ ) of the ocean to melting in Greenland and Antarctica using a different ocean general circulation model. They found a depression of SSH located in the center of the sub-polar North Atlantic and the western subtropical North Atlantic associated with a cold water mass. A reduced meridional overturning circu- 
lation (MOC) in the North Atlantic was also found. In the Southern Ocean, the fresh water inflow, mainly from the West Antarctic Ice Sheet, strengthens the MOC in the southern hemisphere after 30 years. Marsh et al. (2009) forced an eddy-permitting ocean model with fresh water inflow at the Greenland coast from 1991 to 2000. They found only a small impact on large scale ocean circulation. The sea level, caused by density variations, changed mostly in the Baffin Bay because the additional fresh water accumulated west of Greenland.

When mass of a major ice sheet is lost the bedrock below the ice sheet responds to reduced loading with a slow uplift, heavily affecting the sea level. The ongoing Glacial Isostatic Adjustment (GIA) after the last glacial maximum, results in global mean sea level change of about $-0.3 \mathrm{~mm} / \mathrm{yr}$ (Peltier, 2004), which is of the same magnitude as the effect of the estimated mass loss of the West Antarctic Ice Sheet (100 Gt/yr). In addition, the reduced ice mass has smaller gravitational attraction, causing the sea level to fall near the source of changing ice masses and to slightly rise farther away. The resulting fingerprints are discussed by Mitrovica et al. (2001, 2009) for ice mass loss in Greenland, West Antarctica, and of some small mountain glaciers. For the last century they estimated an ice mass loss in Greenland equivalent to about $0.6 \mathrm{~mm} / \mathrm{yr}$. Riva et al. (2010) computed fingerprints of relative sea-level change due to ice mass change of the major glacial regions using GRACE measurements, which are corrected for GIA (Peltier, 2004), and the sea level equation of Farrell and Clark (1976). Globally, Riva et al. (2010) found a eustatic sea-level rise of $1.0 \pm 0.4 \mathrm{~mm} / \mathrm{yr}$ including regional variations caused by decreased gravitational attraction of the reduced ice masses. 
Sea level change caused by gravitational effects have also been investigated in different studies (e.g. Clark and Lingle (1977), Mitrovica et al. (2001), Milne et al. (2009), Mitrovica et al. (2009), Riva et al. (2010)).

Here, the finite element sea-ice ocean model (FESOM,Timmermann et al. (2009); Böning et al. (2008)) is used to investigate the influence of the melting of the GIS on regional and global sea level. Theoretical melting scenarios are introduced into the model. Four different rates of idealized fresh water inflow have been applied $(100,200,500$, and $1000 \mathrm{Gt} / \mathrm{yr})$, as well as a realistic melt sequence to investigate the influence of time-varying melt rates on the sea level. The gravitational effects are analyzed here, which account for the reduced ice mass due to melting (Farrell, 1972; Francis and Mazzega, 1990). These effects are taken into account by applying Green's functions and maps of melt rates, created from melt extent data (Abdalati and Steffen, 2001; Abdalati, 2009). The present study does not account for effects caused by GIA. Also the changes in Earth rotation caused by the mass redistribution, as described by Mitrovica et al. (2001), are not considered here.

\section{Method and data}

\subsection{Finite element sea-ice ocean model}

Ocean circulation and sea level are simulated using the finite element seaice ocean model (FESOM, Timmermann et al. (2009), Böning et al. (2008)). The model solves the primitive equations including the Boussinesq approximation. In order to approximate mass conservation in the model, a correction after Greatbatch (1994) is applied to account for steric effects (Böning, 2009). The model is discretised on a global tetrahedral grid, with its surface 
nodes being $1.5^{\circ}$ apart. The nodes are aligned in the vertical at 26 unequally spaced levels. The bottom nodes are allowed to deviate from the z-levels to realistically approximate the ocean bottom topography. Modeled sea level is computed relative to the equipotential surface (geoid) when the ocean is at rest. Its change is affected by steric effects due to thermal and haline expansion, flow divergence via the continuity equation, and water mass fluxes at the ocean surface. The model is driven by atmospheric wind, pressure and fresh water fluxes (precipitation - evaporation + river runoff).

\subsection{Gravitational effects}

In addition to the steric and mass-driven effects from melt water, a local loss in ice mass also results in a loss of gravitational attraction. This effect does not change the global mean sea level, but strongly affects regional sea level. The direct effect of sea level change due to the deformation of the ocean floor of the elastic Earth caused by loading is not resolved by the ocean model, because modeled sea level is computed with respect to the deformed geoid. Only the indirect effect, that is the gravity anomaly change in the gravity field associated to the Earth's deformation response to load changes leads to small changes in modeled regional sea level (as seen from altimetry measurements). These effects are estimated using Green's functions of Farrell (1972).

The sea level redistribution $S$ due to the gravitational attraction in equivalent water height for a location $(\phi, \lambda)$ is given by the convolution (Francis and Mazzega (1990)) 


$$
S(\phi, \lambda)=\rho_{w} \sum_{i=0}^{N} G_{k}\left(\alpha_{i}\right) F_{i}\left(\phi^{\prime}, \lambda^{\prime}\right) d A_{i} .
$$

$F_{i}\left(\phi^{\prime}, \lambda^{\prime}\right)$ is the change of the water level at location $\left(\phi^{\prime}, \lambda^{\prime}\right)$, where $\phi$ is latitude and $\lambda$ is longitude. $\alpha$ is the spherical distance between $\phi, \lambda$ and $\phi^{\prime}, \lambda^{\prime}, d A_{i}$ is the surface area and $N$ is the number of oceanic elements in the model. In choosing the convolution accuracy is preferred over computational cost (Schrama, 2008). The distribution of the GIS melt is derived from the melt extent estimated by Abdalati and Steffen (2001) and Abdalati (2009), with the mass loss, $F_{i}\left(\phi^{\prime}, \lambda^{\prime}\right)$, converted to equivalent water height before the convolution. The Green's function $G_{k}$ is defined as

$$
G_{k}(\alpha)=\frac{a}{M_{e}} \sum_{n=0}^{\infty}\left(1+k_{n}^{\prime}\right) P_{n}(\cos (\alpha))
$$

where the mean radius of the Earth is denoted as $a$, the total mass of the Earth is $M_{e}$, and $P_{n}$ are the Legendre polynomials (Farrell, 1972). The load love number $k_{n}^{\prime}$ accounts for the indirect gravity effect due to the deformation of the elastic Earth.

\subsection{Reference Simulation}

The reference model simulation is forced with atmospheric fields of the NCAR/NCEP reanalysis (Kalnay et al., 1996). The parameters used are 10 $\mathrm{m}$ wind, $2 \mathrm{~m}$ temperature, specific humidity, total cloud cover and sea level pressure. The fresh water budget includes precipitation and evaporation, which is computed from latent heat flux, also provided by the NCAR/NCEP reanalysis. River runoff is provided by the Land Surface Discharge Model (LSDM, Dill (2008)). The LSDM model uses a seasonally driven discharge 
model for glaciered regions, which ensures that snow accumulation and melting are considered but it does not include estimates of long term ice mass loss or transport of ice. The mass balance of the source terms is not in equilibrium. To avoid unrealistic trends, a two year high pass filter eliminates mass trends in the ocean over longer time scales, following the method of Böning et al. (2008). The simulation is initialized with temperature and salinity values from the World Ocean Atlas (WOA01) and runs from 1958 to 2009 with a time step of 2 hours.

\subsection{Melting scenarios}

Sea level change is calculated by computing the differences between the following model experiments that include the additional runoff due to ice sheet melting and the reference model simulation. All experiments convert the mass flux to an additional fresh water flux at the Greenland coast resulting in an unbalanced long term trend.

\subsubsection{Constant melt rates}

Four simulations have been performed using different mass loss rates along the Greenland coast of 100, 200, 500, and $1000 \mathrm{Gt} / \mathrm{yr}$. The mass losses of 100 Gt/yr and $200 \mathrm{Gt} / \mathrm{yr}$ span the range of observational studies (e.g. Rignot et al. (2008), Wouters et al. (2008), Velicogna (2009)). The two extreme cases are intended to represent scenarios where the mass loss from the GIS has drastically increased. The continuous fresh water flux which is added to the model is evenly distributed along the Greenland coast south of $75^{\circ} \mathrm{N}$ (Figure 1a). The simulations run for 48 years, starting in 1960 . 


\subsubsection{Varying melt rates}

In an additional experiment, the influence of time-varying melt rates on the sea level is investigated. Here, a time series of regional melt rates has been created to investigate the influence of variations in the water inflow. The distribution of the ice mass loss is approximated by using maps of daily melt extent data, defined on a $25 \mathrm{~km} \times 25 \mathrm{~km}$ grid (Abdalati and Steffen, 2001; Abdalati, 2009). The melt extent data provides information about the region and the days, when melting occurs. The total ice melt over five years (805 Gt, Wu et al. (2010)) is then distributed over the melt extent of this period. This results in melt rates of for example $133 \mathrm{Gt} / \mathrm{yr}$ in 2003 and 207 Gt/yr in 2007. Figure 1b shows the total melt of the year 2007 in equivalent water height, with the corresponding water inflow in Figure 1c. Here, the daily mass losses at the different locations are transformed into a fresh water flux and are applied to the nearest coastal nodes. Weekly sea level variations are analyzed from 2003 to 2007 after the daily fresh water inflow fields are included into the model. These results are compared with those found from a melt scenario, where, similar to the first set of experiments, a continuous fresh water inflow of $161 \mathrm{Gt} / \mathrm{yr}$ is evenly distributed along the Greenland coast south of $75^{\circ} \mathrm{N}$ latitude.

\section{Results}

\subsection{Global mean sea level change}

The global mean sea level rises when the GIS melts (Figure 2a). Its amount is given by the amount of ice mass change and the geometry of the model ocean as well as by steric effects. The global mean sea level rises by 
about $0.3 \mathrm{~mm} / \mathrm{yr}$ when $100 \mathrm{Gt} / \mathrm{yr}$ of land ice mass flow as additional fresh water into the ocean, in general agreement with e.g. Hanna et al. (2005), Luthcke et al. (2006), Broeke et al. (2009). In addition, steric effects due to the additional fresh water change the global mean sea level by about one order of magnitude less than the mass-driven contribution (Figure 2b).

Compared to a continuous melt rate, a clear seasonal variability in global mean sea level is predicted in the case of daily varying fresh water inflow (Figure 2c). Here, a strong increase in global mean sea level occurs during the summer months, whereas in winter sea level stays nearly constant, when there is no melting. In fact, during winter and spring, a slight steric decrease in sea level can be observed, for example in the beginning of 2006, due to dynamic effects, which change the heat flux exchange between atmosphere and ocean and hence the sea surface temperature (Figure 2d).

\subsection{Regional sea level change}

\subsubsection{Constant melt rates}

The sea level change is not uniform. Figure 3 depicts the deviation of global mean sea level change after $5,15,35$, and 48 years of model integration for the case of $200 \mathrm{Gt} / \mathrm{yr}$ of melt water being released into the ocean along the Greenland coast. During the first years the sea level rise near the coast of Greenland, mainly in the Baffin Bay and the Labrador Sea, is much higher than the global mean sea level change. After about five years, this sea level anomaly enters the North Atlantic near the east coast of Canada via the Labrador Current. Then it slowly follows the North Atlantic Drift, and reaches Europe after about one decade. From there, the anomaly follows the subtropical gyre to the equatorial region of the Atlantic Ocean while 
another branch enters the Arctic Ocean along the eastern coast. After 48 years, the sea level change anomaly has reached the whole North Atlantic, but the centre of the subtropical gyre is not affected, as also suggested by Gerdes et al. (2006). Different melting scenarios around Greenland lead to a similar spatial and temporal evolution of regional sea level anomalies (Figure 3d-f). Adding fresh water to the model changes the ocean circulation slightly resulting in small variations in atmosphere-ocean fluxes. The changes are small as compared to the direct meltwater response. Here, the pattern of regional sea level change appears to be smoother for higher meltwater source strength because the changes are higher above the noise level than the patterns originating from lower melt rates.

The pattern of the spatial variability in sea level change mostly results from salinity changes due to the fresh water input (Figure 4). The structure of the variations in salinity and temperature in the North Atlantic Ocean at $100 \mathrm{~m}$ depth is very similar to the modeled sea level change, as shown in Figure 3. The negative surface salinity anomaly is a direct consequence of the additional fresh water, which remains in the upper $200 \mathrm{~m}$ above the saltier ocean water, and follows the ocean currents. The sea surface temperature change does not show a specific structure, as it is dominated by the unchanged atmospheric forcing.

In the Baffin Bay, the sea surface salinity is reduced by about 0.2 psu due to the additional fresh water. The correspondingly reduced surface density stabilizes the near-surface water column. This reduces vertical mixing in the upper water layers and the heat exchange between the colder water at the top and the warmer sub-surface water leads to a reduced erosion of the 
temperature maximum at around $450 \mathrm{~m}$ depth. A slight warming between 100 and $1000 \mathrm{~m}$ thus occurs. Also, salinity exchange is decreased in the top $500 \mathrm{~m}$, leading to an increased salinity at around $200 \mathrm{~m}$ depth.

No melt water is transported to the South Atlantic west of Namibia by surface circulation. Hence, there is no significant change of surface water properties. However, the reduced upwelling of cold, fresh water leads to a warming and increased salinity of subsurface water at around the $200 \mathrm{~m}$ level. In the North Atlantic, more fresh water is found at the surface, reducing sea surface salinity by about $0.1 \mathrm{psu}$. The reduced surface density here again increases the stabilization of the near-surface water column, reducing the vertical mixing in the top water layers with less heat exchanged between the warmer surface waters and the colder sub-surface water. The ocean thus warms by $0.1{ }^{\circ} \mathrm{C}$ at $100 \mathrm{~m}$ depth, and cools by $0.01-0.05^{\circ} \mathrm{C}$ at depths between 200 and $1200 \mathrm{~m}$.

After 48 years, the global mean sea level rise is $28.6 \mathrm{~mm}$ with a local maximum of $49.8 \mathrm{~mm}$ along the coast of Nova Scotia (Canada) due to steric effects. The steric effects also lead to more sea level rise along at the European and North American coasts (Figure 5). However, sea level around Greenland falls by $0.14 \mathrm{~m}$ due to the reduced gravitational attraction, leading to a large net decrease in sea level. Note, that the gravitational effect will also cause an additional increase in sea level at distances greater than 70 degree. Hence, sea level in the Southern Ocean will rise slightly faster than the eustatic value. 


\subsubsection{Time varying melt rates}

Ice sheet melting, however, is generally not continuous over time but varies with the seasons. For Greenland, melting occurs mainly in the summer months between July and September. Introducing melt rates with a seasonal cycle into the model allows the variability of melt water inflow to be considered (Abdalati and Steffen, 2001; Abdalati, 2009). The structure of sea level change after five years (Figure 6b) is similar to that of using continuous melt rates of $161 \mathrm{Gt} / \mathrm{yr}$ (Figure 6a). The global mean sea level rises by 0.46 $\mathrm{mm} / \mathrm{yr}$. The regional sea level increases mainly west of Greenland, but in this case, sea level rise is stronger in the Baffin Bay. In the Labrador Sea it is similar to the case of continuous melting. Due to the gravitational effect, ocean water is attracted less and sea level is falling near the Greenland coast by about $6 \mathrm{~mm}$ and in large regions of the Arctic Ocean by about $0.8 \mathrm{~mm}$ after five years. The sea level slightly rises up to $0.5 \mathrm{~mm}$ farther away with a maximum in the Southern Ocean. Note that the regional pattern (Figure 6c) does not account for the change in Earth rotation as discussed by Mitrovica et al. (2001). Total sea level change including the gravitational effect is depicted in Figure 6d. There is only a slight sea level rise along the east coast of Greenland and in the Labrador Sea. An increased sea level in the Baffin Bay remains. In addition, sea level stays almost constant in the Norwegian and Barents Seas. This is seen as a result of the reduced gravitational attraction of the ice sheet balancing the added water volume. 


\section{Conclusions}

Global mean sea level rises by about $0.3 \mathrm{~mm} / \mathrm{yr}$ when the GIS melt at a rate of $100 \mathrm{Gt} / \mathrm{yr}$. Steric effects lead to small additional variations in global mean sea level. These are about one order of magnitude smaller than the direct effect due to the addition of water. Regionally, steric effects lead to high deviations from the global mean sea level change.

The impact of fresh water inflow along the Greenland coast on the oceans is not restricted regionally but distributed over the global ocean. The regional initial sea level change anomalies follow the surface currents and mainly result from changes in temperature and salinity in the upper $200 \mathrm{~m}$. After 48 years the change in steric sea level is distributed through the North Atlantic reaching equatorial regions. In addition, some fresh water enters the Arctic Ocean. Note, that due to the coarse resolution, some weaknesses in the estimated currents in the Norwegian Sea lead to slightly lower fresh water flux into the Arctic Ocean than expected. This will be solved in the future by modeling variations in sea level using a grid with higher spatial resolution.

The decrease in ice mass in Greenland also reduces its gravitational attraction, which leads to lower sea level near the Greenland coast, as well as more sea level rise farther away. Variations in ice sheet melting in Greenland, when compared to continuous melting, influence the sea level change in the North Atlantic, mainly near the source of melting. After five years, the sea level change is more restricted to Baffin Bay with a smaller influence in the Labrador Sea compared to the case of continuous melting.

In future studies, the sea level equation (Farrell and Clark, 1976) will be solved including effects due to GIA, modified Earth rotation and loading. 
In addition, a new model setup having a higher spatial resolution will be used to investigate small scale changes in ocean circulation. Then, new data of Greenland mass loss will be included into the model and results will be compared with different measurements, e.g., derived from tide gauges.

\section{Acknowledgments}

The authors acknowledge support provided by the German Research Foundation (DFG) under grants KU 1207/9-1 and SCHR779/6-1 within the Special Priority Program SPP 1257 Mass Transport and Mass Distribution in the System Earth. We would like to thank the NOAA Climate Diagnostics Center, Boulder, for providing the NCEP/NCAR reanalyzes online at http://www.cdc.noaa.gov. In addition, we would like to thank Robert Dill for providing river runoff from the LSDM model. We acknowledge Waleed Abdalati, who provided the ice sheet melt characteristics of the Greenland Ice Sheet acquired as part of NASA's Program for Arctic Regional Climate Assessment (PARCA) program, available online via the National Snow and Ice Data Center (NSIDC) at http://nsidc.org/data/nsidc-0218.html. The authors wish to thank the reviewers for their constructive comments and suggestions.

\section{References}

Abdalati, W. and K. Steffen (2001), Greenland Ice Sheet Melt Extent: 19791999, Journal of Geophysical Research (Atmospheres), 106 (D24), doi: 10.1029/2001JD900181. 
Abdalati, W. (2009), Greenland Ice Sheet Melt Characteristics Derived from Passive Microwave Data: 1979-2007, Boulder, Colorado USA: National Snow and Ice Data Center, digital media.

Bindoff, N.L., J. Willebrand, V. Artale, A, Cazenave, J. Gregory, S. Gulev, K. Hanawa, C. Le Qur, S. Levitus, Y. Nojiri, C.K. Shum, L.D. Talley and A. Unnikrishnan (2007), Observations: Oceanic Climate Change and Sea Level, in: Solomon, S., D. Qin, M. Manning, Z. Chen, M. Marquis, K.B. Averyt, M. Tignor and H.L. Miller (eds.), Climate Change 2007, The Physical Science Basis. Contribution of Working Group I to the Fourth Assessment Report of the Intergovernmental Panel on Climate Change . Cambridge University Press, Cambridge, United Kingdom and New York, $N Y, U S A$.

Böning, C., R. Timmermann, A. Macrander, and J. Schröter (2008), A pattern-filtering method for the determination of ocean bottom pressure anomalies from GRACE solutions, Geophysical Research Letters, 35, doi:10.1029/2008GL034974.

Böning, C. (2009), Validation of ocean mass variability derived from the Gravity Recovery and Climate Experiment - Studies utilizing in-situ observations and results from a Finite Element Sea-ice Ocean Model, Dissertation, University of Bremen, Bremen, Germany.

Broeke, M. van den, J. Bamber, J. Ettema, E. Rignot, Ernst Schramma, W. J. van de Berg, E. van Meijgaard, I. Velicogna and B. Wouters (2009), Partitioning Recent Greenland Mass Loss, Science, 326 (984), doi: 10.1126 /scince. 1178176 . 
Church, J.A., J.M. Gregory, P. Huybrechts, M. Kuhn, K. Lambeck, M.T. Nhuan, D. Qin, and P.L. Woodworth (2001), Changes in Sea Level, in: J.T Houghton, Y. Ding, D.J. Griggs, M. Noguer, P.J. Van der Linden, X. Dai, K. Maskell, and C.A. Johnson (eds.), Climate Change 2001 The Scientific Basis, Contribution of Working Group I to the Third Assessment Report of the Intergovernmental Panel on Climate Change, Cambridge University Press (Cambridge, New York), 639-694.

Clark, J. A. and C. S. Lingle (1977), Future sea-level changes due to West Antarctic ice sheet fluctuations, Nature 269, 206-209, doi:10.1038/269206a0

Dill, R. (2008), Hydrological model LSDM for operational earth rotation and gravity field variations, Scientific Technical Report; 08/09, Helmholtz-Zentrum Potsdam Deutsches GeoForschungsZentrum, 37, doi: 10.2312/GFZ.b103-08095.

Farrell, W. E. (1972), Deformation of the Earth by Surface Loads, Reviews of Geophysics and Space Physics, 10 (3), 761-79\%.

Farrell, W. E. and J. A. Clark (1976), On postglacial sea level, Geophysical Journal. Royal Astronomical Society, 46, 647-667, doi: 10.1111/j.1365246X.1976.tb01252.x

Francis, O. and P. Mazzega (1990), Global Charts of ocean tide loading effects, Journal of Geophysical Research, 95 (C7), 11,411-11,424.

Gerdes, R., W. Hurlin and Stephen M. Griffies (2006), Sensitivity of a global 
ocean model to increased run-off from Greenland, Ocean Modelling, 12, doi: 10.1016/j.ocemod.2005.08.003.

Greatbatch, R. J. (1994), A note on the representation of steric sea level in models 812 that conserve volume rather than mass, Journal of Geophysical Research, 99, 12,767-12,771, doi:10.1029/94JC00847.

Gunter, B., T. Urban, R. Riva, M. Helsen, R. Harpold, S. Poole, P. Nagel, B. Schutz and B. Tapley (2009), A comparison of coincident GRACE and ICESat data over Antarctica, Journal of Geodesy, 34 (11), 1051-1060, doi: $10.1007 / \mathrm{s} 00190-009-0323-4$.

Hanna, E., P. Huybrechts, I. Janssens, J. Cappelen, K. Steffen and A. Stephens (2005), Runoff and mass balance of the Greenland ice sheet: 1958-2003, Journal of Geophysical Research, 110, D13108, doi: 10.1029/2004JD005641.

Kalnay E., M. Kanamitsu, R. Kistler, W. Collins, D. Deaven, L. Gandin, M. Iredell, S. Saha, G. White, J. Woollen, Y. Zhu, M. Chelliah, W. Ebisuzaki, W. Higgins, J. Janowiak, K.C. Mo, C. Ropelewski, J. Wang, A. Leetmaa, R. Reynolds, Roy Jenne, and D. Joseph (1996), The NCEP/NCAR 40year reanalyses project, Bulletin of the American Meteorological Society, $77,437-471$.

Luthcke, S. B., H. J. Zwally, W. Abdalati, D. D. Rowlands, R. D. Ray, R. S. Nerem, F. Lemoine, J. J. McCarthy, and D. S. Chinn (2006), Recent Greenland Ice Mass Loss by Drainage System from Satellite Gravity Observations, Science,314 (5803), 1286-1289, doi: 10.1126/scince.1130776. 
Milne, G. A., W. R. Gehrels, Ch. W. Hughes and M. E. Tamisiea (2009), Identifying the causes of sea-level change, Nature Geoscience, doi:10.1038/ngeo544

Mitrovica, J. X., M. E. Tamisiea, J. L. Davis, and G. A. Milne (2001), Recent mass balance of polar ice sheets inferred from patterns of global sea-level change, Nature, 409, 1026-1029, doi: 10.1038/35059054

Mitrovica, J. X., N. Gomez, and P. U. Clark (2009), The Sea-Level Fingerprint of West Antarctic Collapse, Science, 323, 5915, p. 753, doi: $10.1126 /$ science. 1166510

Marsh, R., D. Desbruyeres, J. L. Bamer, B. A. Cuevas, A. C. Coward, and Y. Aksenov (2009), Short-term impacts of enhanced Greenland freshwater fluxes in an eddy-permitting ocean model, Ocean Science Discussions, 6, 2911-2937, www.ocean-sci-discuss.net/6/2911/2009/.

Peltier, W. R. (2004), Global Glacial Isostasy and the Surface of the Ice-Age Earth: The ICE-G5 (VM2) Model and GRACE, Annual Review of Earth and Planetary Sciences, 32, 111-149, doi:10.1146/annurev.earth.32.082503.144359

Rignot, E, J. L. Bamber, M. R. van den Broeke, C. Davis, Y. Li, W. J. van de Berg, and E. Van Meijgaard (2008), Recent Antarctic ice mass loss from radar interferometry and regional climate modelling, Nature geoscience, 1, doi: 10.1038/ngeo102.

Riva, R. E. M., J. L. Bamber, D. A. Lavallée and Bernt Wouters (2010), Sea- 
level fingerprint of continental water and ice mass change from GRACE, Geophysical Research Letters, 37, L19605, doi:10.1029/2010GL44770

Schrama, E. J. O. (2008), Three algorithms for the computation of tidal loading and their numerical accuracy, Journal of Geodesy, 78 (11-12), 707-714, doi: 10.1007/s00190-005-0436-3.

Stammer, D. (2008), Response of the global ocean to Greenland and Antarctic ice melting, Journal of Geophysical Research, 113, C06022, doi: 10.1029/2006JC004079.

Tapley, B. D., S. Bettadpur, M. Watkins, and C. Reigber (2004), The gravity recovery and climate experiment: Mission overview and early results, Geophysical Research Letters, 31, L09607, doi:10.1029/2004GL019920.

Timmermann, R., S. Danilov, J. Schröter, C. Böning, D. Sidorenko, and K. Rollenhagen (2009), Ocean circulation and sea ice distribution in a finite element global sea ice - ocean model, Ocean Modelling, 27, 114-129, doi:10.1016/j.ocemod.2008.10.009.

Velicogna, I. (2009), Increasing rates of ice mass loss from the Greenland and Antarctic ice sheets revealed by GRACE, Geophysical Research Letters, 36, L19503, doi: 10.1029/2009GL040222.

Wouters, B., D. Chambers and E. J. O. Schrama (2008), GRACE observes small-scale mass loss in Greenland, Geophysical Research Letters, 35, L20501, doi: 10.1029/2008GL034816.

Wu, X., M. B. Heflin, H. Schotman, B. L. A. Vermeersen, D. Dong, R. S. Gross, E. R. Ivins, A. W. Moore and S. E. Owen (2010), Simultaneous 
estimation of global present-day water transport and glacial isostatic ad${ }_{438}$ justment, Nature Geoscience, 3, 642-646, doi: 10.1038/NGEO938. 
(a)

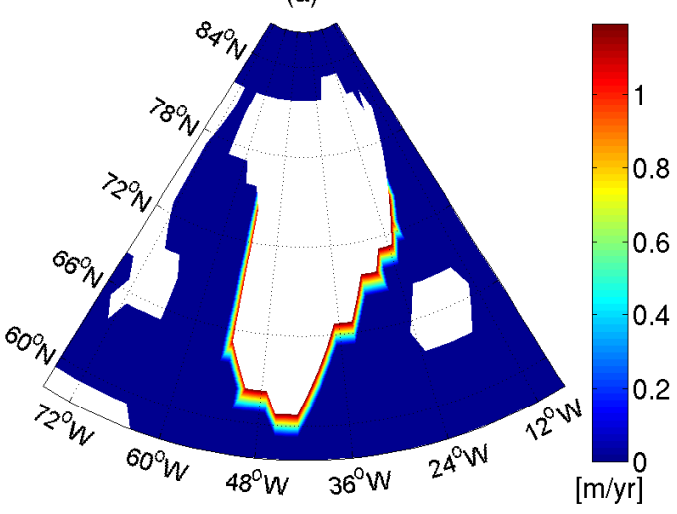

(b)

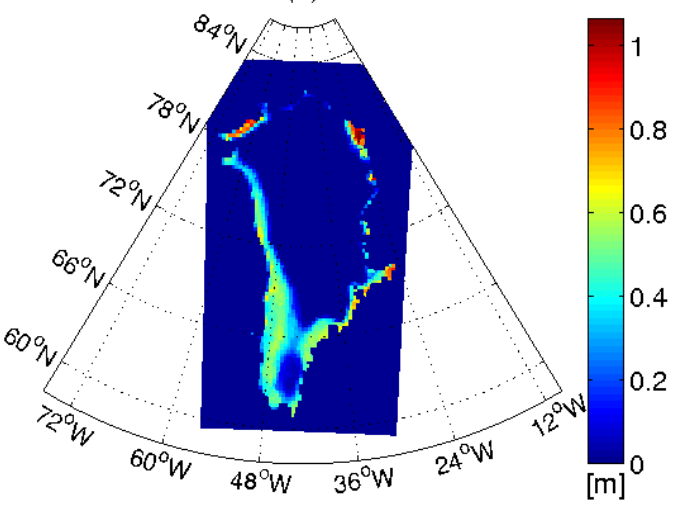

(c)

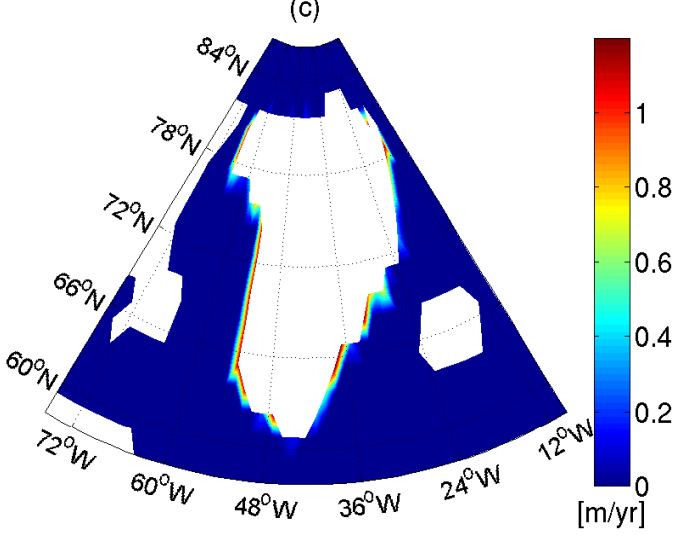

Figure 1: (a) Continuous fresh water inflow (m/yr), due to the melting of the Greenland Ice Sheet (200 Gt/yr), (b) the total loss (in water equivalent) from the Greenland Ice Sheet in 2007 and (c) the corresponding water inflow in equivalent water height (in total 207 Gt) (Abdalati, 2009) 

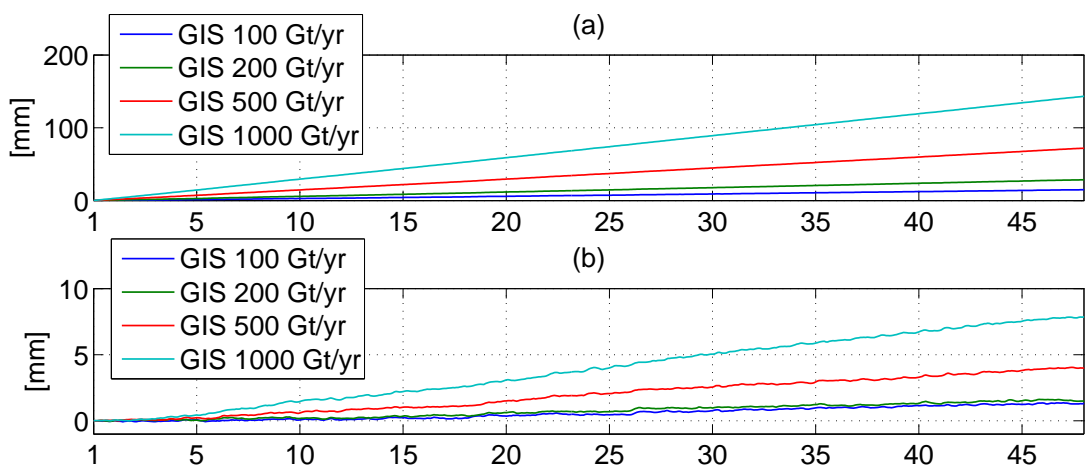

(c)
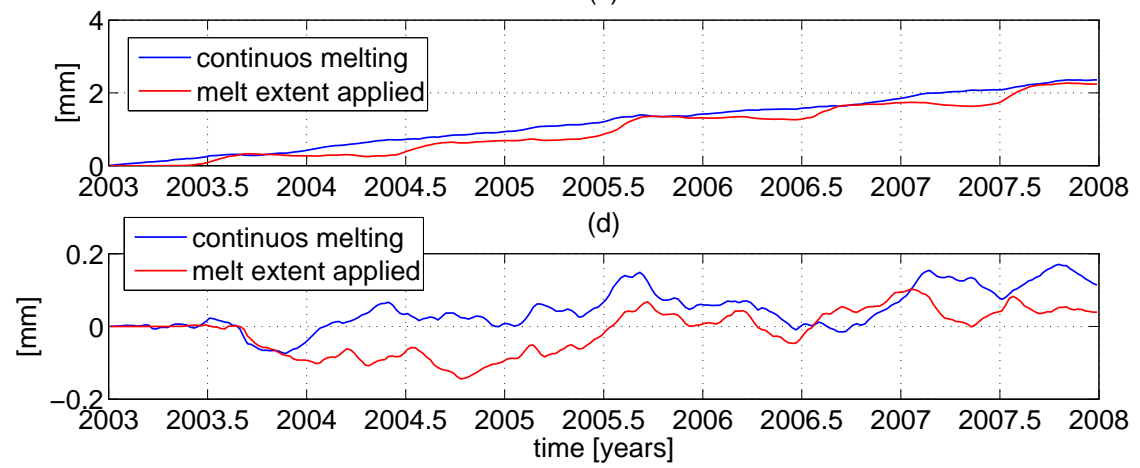

Figure 2: Response of global mean sea level to the melting of the Greenland Ice Sheet (mm), (a) for various continuous melt scenarios over 48 years including the steric contribution, which is shown in (b), as well as (c) the melting of $161 \mathrm{Gt} / \mathrm{yr}$ from 2003 to 2007 for continuous melt (blue line) and melt distributed over melting extent (red line) (d) including the steric contribution shown in (d). 
(a): after 5 years (200 Gt/yr)

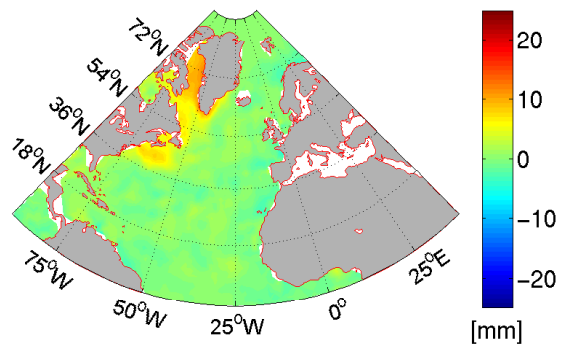

(c): after 35 years (200 Gt/yr)

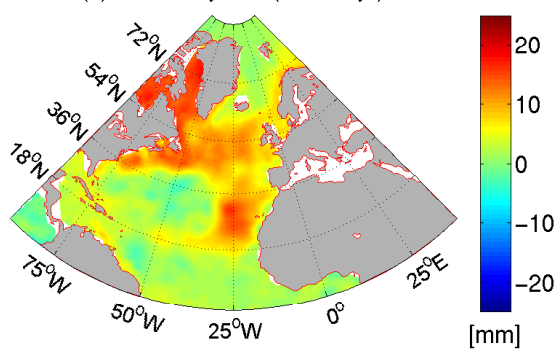

(e): after 48 years (500 Gt/yr)

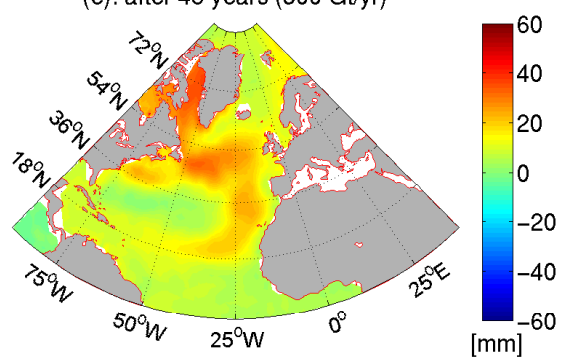

(b): after 15 years (200 Gt/yr)

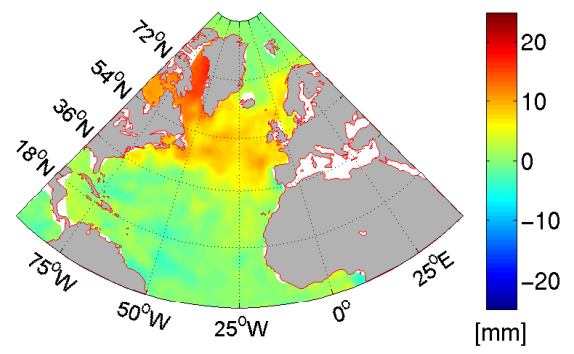

(d): after 48 years (200 Gt/yr)

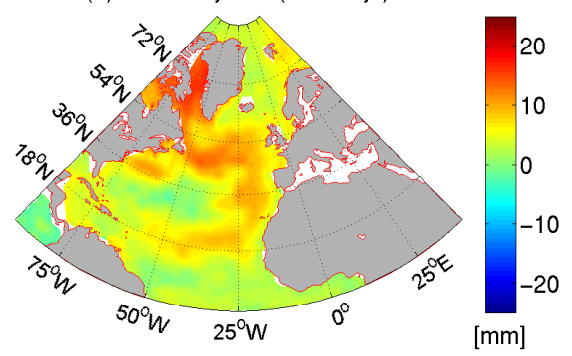

(f): after 48 years (1000 Gt/yr)

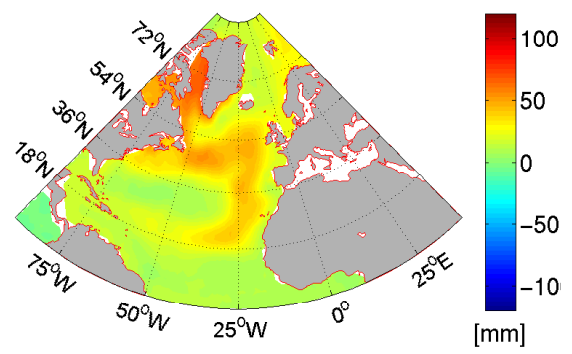

Figure 3: (a-d) Regional sea level change as deviation from its global mean (mm) with respect to the reference model simulation if $200 \mathrm{Gt} / \mathrm{yr}$ of the Greenland Ice Sheet melts, after (a) 5 years, (b) 15 years, (c) 35 years, and (d) 48 years. Sea level change for higher melt rates of 500 and $1000 \mathrm{Gt} / \mathrm{yr}$ are shown in panels (e) and (f), respectively. Note the change in color scale which is scaled according to the source strength. 
(a): $S_{0}$

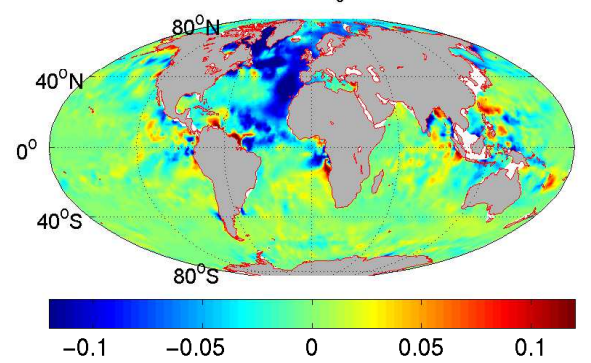

(b): $S_{100}$

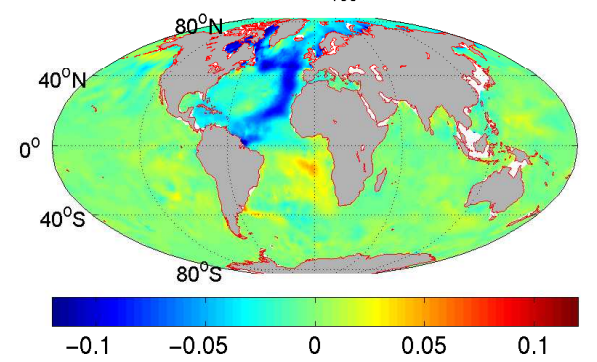

(c): $S_{200}$

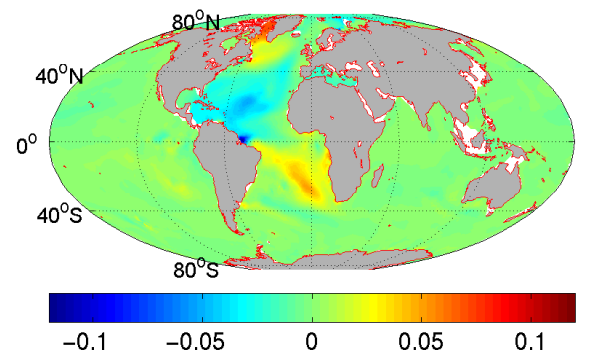

(d): $S_{500}$

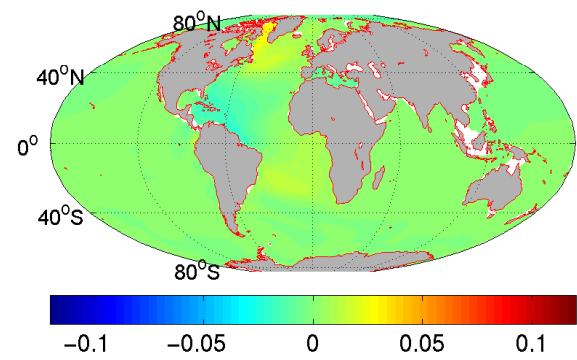

(e): $T_{0}$

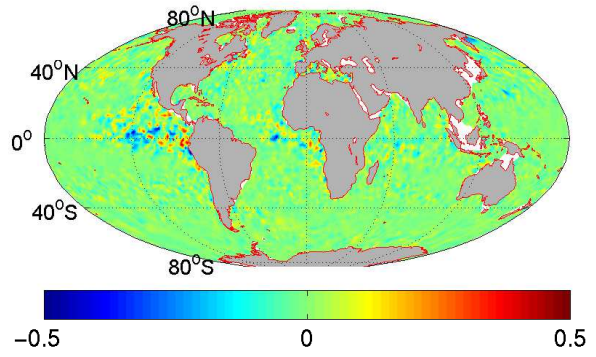

(f): $T_{100}$

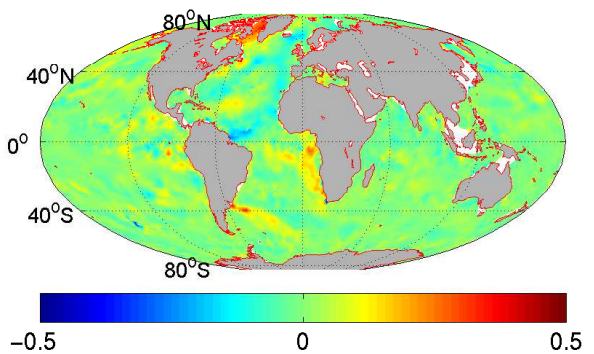

(g): $T_{200}$

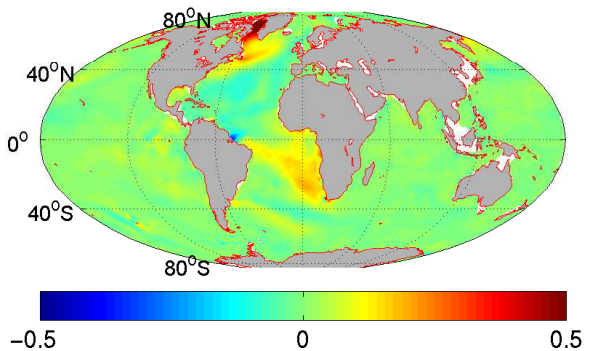

(h): $\mathrm{T}_{500}$

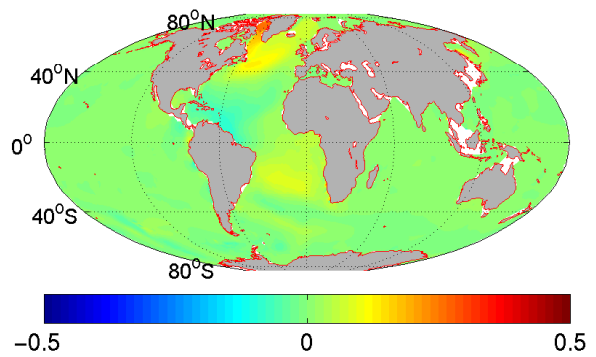

Figure 4: Difference in salinity (psu) and temperature $\left({ }^{\circ} \mathrm{C}\right)$ after 48 years for the scenario of $200 \mathrm{Gt} / \mathrm{yr}$ of Greenland ice being released into the ocean with respect to the reference simulation without additional melt water input; (a) difference in sea surface salinity, and salinity difference at (b) $100 \mathrm{~m}$ (c) $200 \mathrm{~m}$ ang 5 (d) $500 \mathrm{~m}$ depth, as well as (e) difference in sea surface temperature, and temperature difference at (f) $100 \mathrm{~m}$, (g) $200 \mathrm{~m}$ and (h) 500 m depth 
(a)

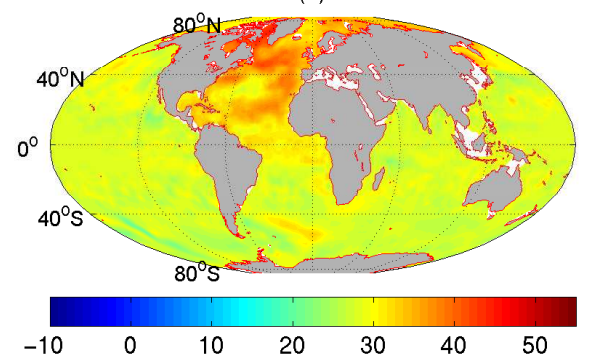

(b)

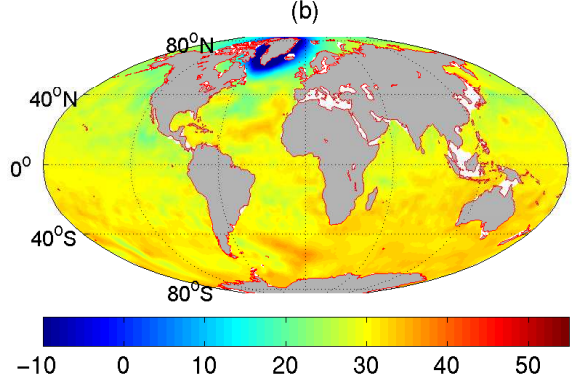

Figure 5: Sea level change $(\mathrm{mm})$ with respect to the reference model simulation resulting from the Greenland Ice Sheet melting at a rate of $200 \mathrm{Gt} / \mathrm{yr}$ after 48 years; (a) sea level change with respect to an undisturbed geoid including regional and global mean sea level change and (b) sea level change with respect to the adjusted geoid as seen from altimetry after adding the gravitational effect due to Greenland ice mass loss 
(a)

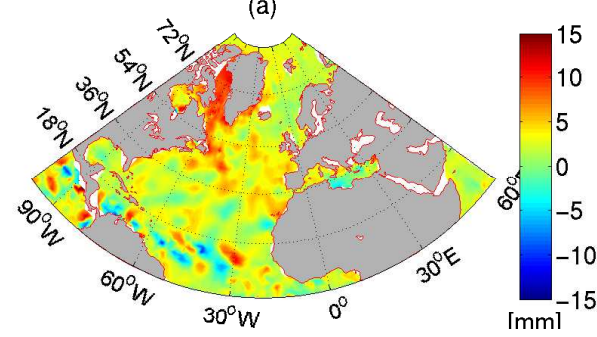

(c)

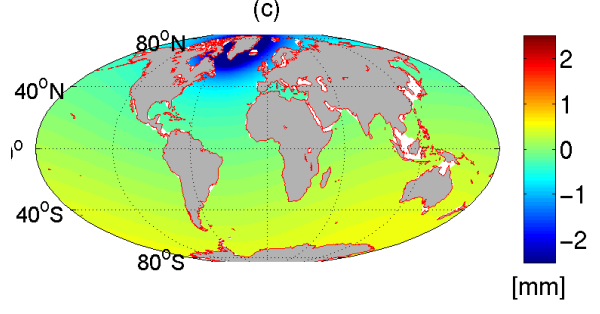

(b)

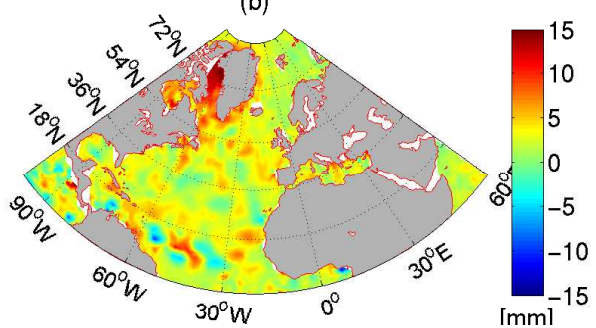

(d)

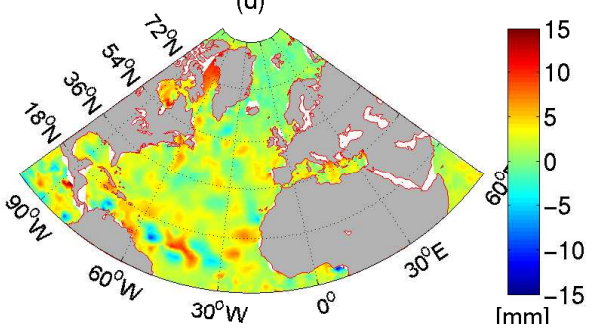

Figure 6: Sea level change $(\mathrm{mm})$ with respect to the reference model simulation resulting from Greenland Ice Sheet melting of $161 \mathrm{Gt} / \mathrm{yr}$ after 5 years (2003-2008), (a) with continuous melting equally distributed at coastal nodes south of $75^{\circ} \mathrm{N}$, (b) distributed to the melt extent (Abdalati and Steffen, 2001; Abdalati, 2009), (c) sea level change due to the gravitational effect of Greenland ice sheet melting of $805 \mathrm{Gt}$, corresponding to $2.35 \mathrm{~mm}$ mean sea level equivalent, and (d) the total sea level change including regional and global mean sea level change and the gravitational effect related to Greenland Ice Sheet melting 